Post-print of Huvila, I.; Enwald, H.; Eriksson-Backa, K.; Hirvonen, N.; Nguyen, H. \& Scandurra, I. Anticipating ageing: Older adults reading their medical records. Information Processing \& Management, 2018, 54(3), 394 - 407. DOI: 10.1016/j.ipm.2018.01.007

\title{
Anticipating ageing: Older adults reading their medical records
}

\author{
Isto Huvila $^{\mathrm{a}^{*}}$, Heidi Enwald ${ }^{\mathrm{b}}$, Kristina Eriksson-Backa ${ }^{\mathrm{c}}$, Noora Hirvonen ${ }^{\mathrm{b}}$, Hai Nguyen ${ }^{\mathrm{c}}$ \\ and Isabella Scandurra ${ }^{\mathrm{d}}$ \\ a Department of ALM, Uppsala University, Sweden, and Information Studies, Åbo Akademi University, Finland \\ ${ }^{\mathbf{b}}$ Information Studies, University of Oulu and Åbo Akademi University, Finland \\ ${ }^{\mathbf{c}}$ Information Studies, Åbo Akademi University, Finland \\ dörebro University, Sweden \\ *isto.huvila@abm.uu.se
}

\section{Highlights}

- Older adults, who are still active in working life but approaching retirement, differ from other age groups by their health information behaviour

- Older adults are the least confident and least motivated to use online health information.

- Difficulties in understanding and accepting health information do not necessarily apply to medical records, i.e. health information about oneself

- The results do not indicate an obvious linear relationship between age and motivation to use online health information

- Personal health information management is a central aspect of health information behaviour

\begin{abstract}
In spite of the general interest in health information behaviour, there is little earlier research on how older adults, who are still active in working life but approaching retirement, differ from other age groups. A survey with Swedish patients who had ordered and read their medical record was conducted to to map the preferences and motivations of older adults (born 1946-1960) ordering a copy of their medical record, and using medical records based e-health and information services in the future. The results do not indicate an obvious linear relationship between age and motivation to use online health information but show several differences between the age groups. Older adults were less interested in communication with their medical doctor by e-mail. Yet, they had searched health information in the Internet during the last week more likely than young. They were more inclined to read medical record to get an overview of their health than young, but less confident that they understood most of the content or turn to their family and friends to seek help than the elderly. When compared to younger adults and elderly people, older adults are the least confident and least motivated to use online health information. It is suggested that older adulthood can be seen as a transitory stage of life when the need of health information increases and engagement with health changes. The results agree with prior research on the potential usefulness of (online) medical records as a way to inform citizens. However, specific provision strategies may be necessary to match the needs and motivations of different age groups.
\end{abstract}


Keywords: health information behaviour; medical records; older adults; health information; personal information management

\section{Introduction}

The population is ageing rapidly in many developed countries. People are encouraged and required to engage (Mockford et al., 2012) and take a more active role in managing their own health. Participating in decision-making related to health and medical care has been identified as a potential remedy to the challenges faced by healthcare systems around the world (Nease et al., 2013; Hibbard et al., 2013). A central premise for being informed and able to make decisions regarding health and healthcare is to have access to health information and medical documentation relating to one's own current condition, previous and planned treatments, and visits to healthcare providers (de Lusignan et al., 2014; Clarke et al., 2016). This can be seen as part of personal health information management (PHIM) (e.g., Pratt et al., 2006, Lustria et al., 2011, Ancker et al., 2015).

An adequate understanding of the health information behaviour of older citizens is crucial for development of services and systems for health information seeking and retrieval (Sanchiz et al. 2017), and providing such information for this group in a manner that would encourage and help them to become better informed and to take more responsibility for their healthcare. Understanding the actual health information behaviour and its premises is pivotal for avoiding idealised assumptions of the over-rationality of patients and categorising their behaviours as bad (Johnson, 2014). With older citizens, this is especially vital in the group of older adults who are approaching old age but are still active in working life, and on average, have many years of life ahead. In comparison to old elderly, older adults have been suggested to be more knowledgeable of recently introduced technologies and with them, the use of e-health technologies and health behaviour change has been argued to have a more significant impact than with elderly individuals with shorter expected remaining life-time (Nikou, 2015). In spite of the growing corpus of research on older citizens, their health (WHO, 2015), health information literacy (Yates et al., 2012; Eriksson-Backa, 2013; Eriksson-Backa \& Ek, 2015; Enwald et al., 2017), and health information behaviour (Eriksson-Backa, 2011; Medlock et al., 2015), there are still relatively few studies that investigate specific characteristics of this group and how older patients differ from other age groups (Huvila et al., 2016). Furthermore, as the typical focus on ageing suggests, much of the earlier research has treated the elderly population as a relatively homogenous group although there are major differences between older adults who are still active in working life, the ones who have retired only recently, and the age group of the oldest old (Asla \& Williamson, 2015). In addition, none of these groups are homogenous, either.

This article reports on how older adults (born 1946-60) differ from younger or older individuals concerning their health information behaviour and their preferences regarding reading of medical documentation, and use of online e-health services. The analysis is based on the results of a survey of individuals $(\mathrm{N}=354)$ who have ordered a copy of their medical records from a regional healthcare authority in a Swedish county.

\section{Background}

There is a lot of research relating to health information and health information behaviour (Case \& Given, 2016), health information literacy (Suri et al., 2014), searching and retrieval of health 
information (Zhang, 2014), and different aspects of medical records from preservation (e.g. Dong, 2015; Stanberry, 2011) to how they are used by patients (e.g. Huvila et al., 2016; McNamara et al., 2015) and healthcare professionals (e.g. Grünloh et al., 2016; Shaw, 2013), both in information science and related fields. Instead of attempting to review the entire field, the following section reviews the issues of health information, e-health, and medical records related research that are pertinent to this study: patient engagement, information access, access to medical record information, and ageing with a focus on older adults (i.e. patients) and healthcare perspectives to providing access to information.

\subsection{Patient engagement and access to information}

Engaging patients is internationally recognized as a key factor in improving health service delivery and quality (Mockford et al. 2012) and is found to have a positive impact on the development and evaluation of purposeful health information technologies (Darking et al., 2014) and health outcomes and also, albeit to a somewhat lesser degree, healthcare costs (Hibbard \& Greene, 2013). In general, patient engagement refers to the level of patients' activation: an engaged patient as "an active agent in the management of his/her own health" (Hibbard et al., 2004). Gruman et al. (2010) define patient engagement as the actions individuals may enact to participate knowledgeably and actively in their own healthcare to realize its full benefit. Part of the patient engagement movement is providing patients access to their own medical records and other health related information. Today, patients have to take care and be aware of many types of personal health information. This relates to personal health information management (PHIM) (e.g., Lustria et al., 2011; Ancker et al., 2015; Hartzler et al., 2017) where an engaged patient may become more aware of his symptoms, diagnosis and treatments and use healthcare more efficiently. The findings of Hoerbst et al. (2010) in a study of Austrian and German patients suggest that in general population, patients have interest in PHIM. Making patients co-producers of their health can enhance their satisfaction with the healthcare system as well as their responsibility in both care and prevention and thus improve clinical outcomes and reduce health delivery costs (Graffigna et al., 2014).

There has for long been a debate about the informed patient and a 'partnership' between practitioners and patients as well as a notion of 'informed choice'. It is thought that informed patients are better at assessing risks and benefits of treatments (e.g., Henwood et al., 2003, Karnam \& Raghavendra, 2017; McColl-Kennedy et al., 2017). Engaged and informed patients are expected to take more responsibility for their own health (Henwood et al., 2003; Graffigna et al., 2014) but this is not only achieved by being provided information passively, also one's own activity including seeking of information is required (Lloyd et al., 2014). Information about health is, however, often available from different sources and is presented from different angles, and it has been said that in the complex and often confusing situations where it is obtained, a person needs to master the information (Eriksson-Backa et al., 2012). In order to become informed, certain competencies and skills related to information itself and use of sources, also called information literacy, are relevant, and being uninterested in, for example, validity issues can act as a "constraint on the emergence and enactment of the informed patient identity" (Henwood et al., 2003, 604).

\subsection{Ageing and access to health information}

It has been found that people's relationship with health information may become more intense with increased age (Niemelä, 2006, 121) and deteriorating health may raise specific health 
information needs (Alpi \& Bibel, 2004). A recent study on the web searching of retired older and non-retired younger adults showed that the older respondents' knowledge of the health domain compensated for their age-related decline of cognitive flexibility (Sanchiz et al., 2017). Although seeking health information is considered an indicator of a proactive attitude towards health (Pálsdóttir, 2008; Ek \& Heinström, 2011; Johnson \& Case, 2012, 17; Jung, 2014), poor health has also been associated with more active information seeking (Renahy et al., 2008). One reason for the contradictory findings is that people also seek health information for others (Zickuhr, \& Madden, 2012; Pew Research Center, 2013). Moreover, the type of information sought may play a role in explaining these findings: reasons for seeking wellness information differ from those associated with illness information seeking (Weaver et al., 2010).

Needs experienced by individuals that often lead to seeking of health information, include the need for acknowledgement, the need for reduction of uncertainty, and the need for perspective (Caiata-Zufferey et al., 2010). Some information needs relate to situations of medical consultation. Attfield, Adams, and Blandford (2006) found that before a clinical encounter, information was sought to assess whether medical consultation was needed at all, or where to get the best specialist help. When an appointment was arranged, background knowledge about conditions and treatments was desired, to help to be more knowledgeable about the justification of practitioners' proposals and to be able to form own opinions. After a visit, information was needed for a general understanding and a clarification of a diagnosis, as well as to decide about the appropriateness of a treatment and to learn about possible side-effects. Li et al. (2014) found that patients often search online health information after a visit, mainly because of curiosity, but also due to dissatisfaction with the completeness or accuracy of information provided by the physician. Among older adults, acquiring online health information before visits to doctors can save time and improve the communication and the quality of the visit, as well as the patient's knowledge leaving the patient with a better capability to discuss treatments and make decisions (Taha, Sharit \& Czaja, 2009).

In a small survey of Finns in retirement age, the respondents claimed that they need health information the most when they are about to undergo medical treatment, or when they feel ill. Some respondents had, however, answered that they instead needed information after the visit, in order to find out more about their condition (Eriksson-Backa, 2011). Older adults may, for example, turn to the Internet after an appointment to find information that could explain what was actually discussed (Eriksson-Backa, 2013).

The ageing process not only involves physical changes, but also psychological and social effects (Wrzus et al., 2013) and the changes may affect access to and utilization of health information (Kaphingst et al., 2014). In addition, preferences for certain sources and attention to messages may be influenced (Sparks \& Nussbaum, 2008). One reason for preferring a certain information source may be impairments such as deteriorated eyesight, requiring certain material formats (Alpi \& Bibel, 2004). In their study among people over 65-year-old, Enwald et al. (2017) found that the older the respondents were, the more likely they were to avoid information and to agree that health information is often too lengthy, too scientific and mostly aimed at young people. Especially people in the oldest age group (80 years or older) had difficulties in understanding and accepting health information.

Health professionals including physicians, other healthcare staff, and pharmacy staff are often preferred as information sources for medical information (Renahy et al., 2008; Taha et al., 2009; Eriksson-Backa, 2013; Gutierrez et al., 2014; Medlock et al., 2015), followed by friends and 
family, and different types of media including the internet (Niemelä, 2006, 121-122; Zickuhr \& Madden, 2012; Medlock et al., 2015). Older adults have been found to use medication information such as patient information leaflets or prescriptions rather actively, as well (ErikssonBacka, 2013).

Older adults often search online information about illness or medical conditions, information about a doctor, hospital or the like, nutrition, insurance, and prescription drugs (Taha, Sharit \& Czaja, 2009). Needs for additional information on symptoms, prognosis and treatment options were reasons for online searches mentioned by Medlock et al. (2015). Among Finnish respondents aged 65-79 years, the results show a digital divide. The oldest respondents, those with lower levels of education, and those who rated their health as poor, used the internet less than younger ones to find health information (Eriksson-Backa, 2013). Other studies have connected older age, lower levels of education, and poorer health with non-use of the internet, as well (Gilleard \& Higgs, 2008; Ek \& Niemelä, 2010; Yan, 2010; Kontos et al., 2014).

To be able to act as an active agent in healthcare, people also need to be able to understand and act on health information (see e.g. Chin et al., 2015). Those who have higher levels of both health literacy (HL), that is, the ability to obtain, understand, and use health information (e.g. Sørensen et al., 2012), and health information literacy (HIL), which is understood as higher level cognitive abilities to realize the need for health information, and to select sources, use them to retrieve information and evaluate, understand, and use this information for the benefit of one's health (e.g., Eriksson-Backa et al., 2012, Niemelä et al., 2012; Hirvonen et al., 2016; Enwald et al., 2017) seem to be better at managing health information. Health information literacy has been shown to be related to perceptions of health communication among older adults; those with higher HIL levels are more positive to experiences of communication in healthcare contexts (Eriksson-Backa \& Ek, 2015). It has, furthermore, been found that older adults have lower health literacy than younger adults (Berens et al., 2016; Wu et al., 2016). Inadequate health literacy and health information literacy can therefore be barriers to engagement (see e.g. Chin et al., 2015).

\subsection{Patient access to medical record information}

From the healthcare provider perspective, the aim of providing not only healthcare staff but also patients access to healthcare data is to improve, for example, the safety, quality, sustainability and effectiveness of care by engaging patients in their own care (Ammenwerth et al., 2012; e.g.; Regeringen, 2016; European Commision, 2017). However, a systematic review (de Lusignan et al., 2014) found a lack of evidence of the impact of online access but also a growing tension between a growing demand for accessing the information and the healthcare system that is not ready to meet these expectations (de Lusignan et al., 2014). From healthcare point of view, the expected outcomes of provider initiated access to medical record information and electronic health records are largely similar to those of patient controlled personal health records (PHR). Connecting for Health, the Personal Health Working Group (2003) define PHRs as (usually Internet-based) "set[s] of tools that allow people to access and coordinate their lifelong health information and make appropriate parts of it available to those who need it". Similarly to online access to medical records, PHRs have been suggested to give control to the consumer and may provide patients with autonomy and empowerment (Vance et al. 2015).

Healthcare professionals have had several concerns about giving patients online access to their health information, including the possibility of negative impact on workload, risks to privacy, and increased anxiety of patients (Scandurra et al., 2017; Grünloh et al., 2016;). A related concern is that professional medical record information can be difficult to use by patients (Huvila et al., 
2016) similarly to how PHR information can be difficult to use by healthcare providers (Romero et al., 2012). However, in contrast to these concerns, a Swedish qualitative study with cancer patients showed that online access did not generate substantial anxiety, concerns, or that it would have increased telephone contacts with healthcare unit (Rexhepi et al., 2016). The interviewed patients used the PHR as a memory aid, to prepare for the next visit, to learn more about their medical issues and also reported that it helped them to feel more in control of their care (Rexhepi et al., 2016).

The findings of de Lusignan et al. (2014) indicate that access to their electronic health record and related services offer patients increased convenience and satisfaction. In a focus group study by Zarcadoolas et al. (2013), individuals were enthusiastic about patient accessible medical records and perceived that they might have great utility and value. Noblin (2010) found that a majority of the respondents in her study expressed intention to use a personal health record if it was made available to them. There are, however, differences in different age and demographic groups. Gordon and Hornbrook (2016) found that over 70 year olds were less likely than 65-69 year olds to be registered to use a patient portal. Among those who were registered, the older patients were less likely to have used the portal to send messages, order prescription refills, or view laboratory test results.

In addition to access, the ability to master health information is an important prerequisite to a use of personal health data, including medical record information. According to a study by Woods et al. (2013), older patients felt that seeing their health records had a positive impact on communication with providers, enhanced knowledge of their health, improved self-care, and allowed a greater participation in care quality. At the same time, seeing previously undisclosed information, derogatory language, and inconsistencies in notes caused challenges for the patients (Woods et al. 2013). The intentions to use such a service was, however, affected by their perceived usefulness, comfort level with technology, level of health literacy, and socioeconomic status. Barriers to access electronic health records such as privacy and security concerns, costs, integrity, accountability, and low level of health literacy, have also been found. Vance et al. (2015) suggest on PHRs that when patients and providers believe that the information is safe, accurate, reliable, and applicable for improving health, they are more likely to be used. Walker et al. (2017) results suggest further that eventual security concerns are less likely to lead to withholding of information among older population $(50+)$ than with younger patients. Furthermore, Young et al. (2014) found that among older adults, key barriers for the adoption of PHR included technological discomfort, privacy or security concerns, lack of relative advantage, and an undesirable user representation (users thought that the systems were not meant for them).

In spite of the intensive research on different approaches to provide patients access to their medical record information, there is still a lack of conclusive evidence. According to a review by Irizarry, DeVito Dadds and Curran (2015): 'current research has demonstrated that patients' interest and ability to use (electronic) patient portals is strongly influenced by personal factors such age, ethnicity, education level, health literacy, health status, and role as a caregiver."

\section{Research objective}

The research objective of this study is to map the preferences and motivations of older adults ordering a copy of their medical record, and using medical records based e-health and information services in the future in order to (1) understand how citizens of different ages (young, older adult, and the elderly) differ in terms of their preferences and motivations for using this information, and to (2) understand the implications that differences in these preferences and 
motivations among the age groups hold for the provision of healthcare information for citizens of varying ages. The research questions are: RQ1: How do the preferences and motivations of older adults (born 1946-1960) differ from younger and older (i.e. elderly) people, and RQ2: What implications do the specific preferences and motivations of engaging oneself in reading medical records and using e-health services have on the provision and management of health information for the members of this group.

\section{Methods and material}

The data were collected with a questionnaire survey as a part of the larger research project $\mathrm{XX}^{* *}$ that focused on the premises and implications of online patient access to medical records. The questionnaire included contextual information on the respondents' self-perceived health, health information behaviour, and demography. The survey instrument consisted of 39 questions on the preferences and motivations of reading medical records and using e-health services. Of these, 9 question sets, consisting of 53 statements on a 5-point Likert scale, were analysed closer in the present study to reveal possible differences between younger and older respondents. The questionnaire was constructed on the basis of earlier questionnaires (Fowles et al., 2004: Ekendahl, 2011;) and complemented with additional questions developed by the researchers on the basis of their expertise and the specific aim of the study. The questions and statements are listed in Tables 1-8. The same data has been analysed earlier from other perspectives in Author(s) 2015** and Author(s) 2016**. Under Swedish legislation, no ethical approval was necessary, because participation in the survey was voluntary, all respondents were adults and were granted full anonymity, and no personal data was collected.

The survey was sent to all patients who ordered a paper copy of their medical record from a Swedish county council in June-August 2012. The process continued until 1,000 survey forms had been mailed. No reminders were sent. The response rate was $35.4 \%(\mathrm{~N}=354)$. An invitation to participate in the study and a survey form were mailed to the respondents in the same envelope as a copy of their record. Respondents were also offered the option of filling in the survey online. Of the respondents $15.5 \%(\mathrm{n}=55)$ used this option. The mailing of the survey forms and the online survey were administered by the county council. The survey procedure has been described in detail in Author(s) 2016**.

The data were analysed with SPSS 23.0 using Kruskal-Wallis and Pearson Chi-Square tests, as appropriate, with a 95\% confidence interval to investigate how the group of respondents labelled as Older Adults (28\% of respondents), born 1946-1960 (by the time of data collection between 51 and 66 years old) differ from those born after 1961 (i.e. younger than 51 by the time of data collection) labelled as Young (52\%), and those born before 1946 (older than 66 when the data was collected) labelled as Elderly (20\%).

\section{Results}

\subsection{Sample characteristics and general findings}

Seventy-four percent (233 of 343) of the respondents were female and 26\% (90 of 343) male. Thirty-seven percent (131 of 350) were employed, 7\% (23 of 350) entrepreneurs, 4\% (13 of 350) unemployed, 10\% (35 of 350) on parental leave, 9\% (30 of 350) on medical leave, $0.6 \%$ ( 2 of 350 ) on part-time medical leave, 4\% (13 of 350) full-time students, and 27\% (96 of 350) were retired. Eighty-four percent (286 of 342) had at least secondary- or upper-secondary-level education. Three percent (10 of 342) had no formal education. Sixty-six percent (219 of 334 ) 
used the Internet at least an hour every day. Nine percent (31 of 334) were nonusers of the Internet. Ninety-two percent (310 of 338) had Internet access at home.

A comprehensive descriptive analysis of the results of the survey can be found in Author(s) $2016^{* *}$. In general, the respondents were relatively satisfied with their health (mean 3.66, SD 1.307 on a five-point scale) and they considered that it would be a very good idea to be able to read medical records online (mean 4.1, SD 1.253). They were also highly confident that they understood most of the content in their medical records (mean 4.30, SD 0.879) and even more so with the parts they were interested in (mean 4.43, SD 0.807).

The most prominent reasons to order a copy of the record were to get an overview of their health or condition (mean 3.94, SD 1.512), to check or verify some details (mean 3.59, SD 1.623), and general interest (mean 3.22, SD 1.673). The respondents were most inclined to seek information by themselves e.g., on the Internet (mean 3.92, SD 1.374) and ask healthcare staff during their next visit (mean 3.74, SD 1.44) if they did not understand something in their medical record. The most significant implications of being able to read their medical records were that the respondents considered that they will be able to understand their health or condition better (mean 4.02, SD 1.185), they thought that it improves communication between them and healthcare professionals (mean 3.90, SD 1.228), and that they could keep the medical record for their own records (mean 3.90, SD 1.336).

The respondents were generally optimistic about the usefulness of suggested information services based on the information found in their medical record (see Table 6 for alternatives). Only the ability to manage services for other people (e.g., letters of referral, vaccinations and medication lists) with mean 2.99 and standard deviation of 1.537 , and the ability to write their own comments in the text of the record (mean 3.49, SD 1.393) scored below 3.5 on the five-point scale.

Internet was an important source of health information for the respondents (mean 3.55, SD 1.461). They were also inclined to like to communicate with medical doctors using email (mean 3.22 , SD 1.651) but less likely to use social media for health information (mean 1.61, SD 1.084).

Young respondents (Table 1a) were more likely to think that they are in good health than the Older Adults $\left(\chi^{2}(2)=4.935, \mathrm{p}<.001\right)$ or Elderly $\left(\chi^{2}(2)=3.475, \mathrm{p}=.002\right)$. Similarly, they were less worried about their health than other respondents (Younger vs. Older Adults $\chi^{2}(2)=3.983$, $\mathrm{p}<.001$, Younger vs. Elderly $\left.\chi^{2}(2)=3.980, \mathrm{p}<.001\right)$. The Younger and Older Adults were less likely to have chronic conditions than the Elderly respondents (Table 1b).

\subsection{Differences between the young, older adults, and elderly}

The analysis shows that Older Adults (born 1946-1960 i.e. between 52 and 66 years old by the time taking the survey) differed significantly from Elderly and Young respondents in several aspects. The findings regarding significant differences and similarities are reported below according to the four surveyed themes 1) reasons for ordering a copy of medical record, 2) contents of the medical record, 3) the meaning of reading medical records, and 4) online e-health services and information.

Table 1a: Questions about health. 


\begin{tabular}{|l|l|l|l|l|l|}
\hline Statements & Chi-Square & Sig. & $\begin{array}{l}\text { Young } \\
(\mathbf{n = 1 7 1})\end{array}$ & $\begin{array}{l}\text { Older Adults } \\
(\mathbf{n = 9 4 )}\end{array}$ & $\begin{array}{l}\text { Elderly } \\
(\mathbf{n = 6 7 )}\end{array}$ \\
\hline My health condition is very good. & 28.837 & $<.001$ & 181.39 & 125.02 & 134.67 \\
\hline I am very worried about my health. & 24.625 & $<.001$ & 126.03 & 169.98 & 180.48 \\
\hline I often think about my health. & 4.625 & .099 & 137.02 & 159.81 & 150.53 \\
\hline
\end{tabular}

Table 1b: Questions about health.

\begin{tabular}{|c|c|c|c|c|c|c|c|c|}
\hline & & & \multicolumn{6}{|c|}{ Standardised residuals (Chi-Square)* } \\
\hline Statements & Chi-Square & Sig. & \multicolumn{2}{|c|}{$\begin{array}{c}\text { Young } \\
(\mathrm{n}=171)\end{array}$} & \multicolumn{2}{|c|}{$\begin{array}{c}\text { Older Adults } \\
(\mathrm{n}=94)\end{array}$} & \multicolumn{2}{|c|}{$\begin{array}{l}\text { Elderly } \\
(n=67)\end{array}$} \\
\hline & & & Yes & No & Yes & No & Yes & No \\
\hline I have several chronic conditions ( $\mathrm{Yes} / \mathrm{No}$ ) & 58.424 & $<.001$ & -3.3 & 3.9 & 2.3 & -2.8 & 2.6 & -2.9 \\
\hline
\end{tabular}

Reasons for ordering a copy of the medical record (Table 2): Elderly respondents $\left(\chi^{2}(2)=4.249, \mathrm{p}<.001\right)$ and Older Adults $\left(\chi^{2}(2)=2.430, \mathrm{p}=.045\right)$ were more likely to have ordered a copy of the medical record to get an overview of their health or condition than the Young respondents. In the inclination to order a copy to verify or control details in the record there were no differences between Older Adults and other respondents, only significant difference being between Young and Elderly respondents $\left(\chi^{2}(2)=2.690, p=.021\right)$, of which the latter were more likely to have that particular reason. In contrast, Older Adults $\left(\chi^{2}(2)=2.981, \mathrm{p}=.009\right)$ and Elderly $\left(\chi^{2}(2)=3.300, p=.003\right)$ respondents used the medical record to follow-up what was said during their last visit to a larger extent than Young respondents. Using the medical record to involve family members in their care was a more significant reason for Elderly respondents than for Older Adults $\left(\chi^{2}(2)=3.942, \mathrm{p}<.001\right)$ or Young $\left(\chi^{2}(2)=5.568, \mathrm{p}<.001\right)$.

Table 2: Reasons for ordering a copy of medical record.

\begin{tabular}{|l|l|l|l|l|l|}
\hline & & & \multicolumn{3}{|c|}{ Mean Rank (Kruskal-Wallis) } \\
\hline Statements & Chi-Square & Sig. & $\begin{array}{l}\text { Young } \\
(\mathbf{n = 1 7 1})\end{array}$ & $\begin{array}{l}\text { Older Adults } \\
(\mathbf{n = 9 4 )}\end{array}$ & $\begin{array}{l}\text { Elderly } \\
(\mathbf{n}=\mathbf{6 7})\end{array}$ \\
\hline I ordered a copy of my medical record because of & & & & & \\
\hline Of general interest & 1.622 & .444 & 136.97 & 123.95 & 135.13 \\
\hline To get an overview of my health/condition & 19.723 & $<.001$ & 128.33 & 153.22 & 179.98 \\
\hline To check/verify some details & 7.540 & .023 & 128.68 & 142.00 & 162.83 \\
\hline Because I was unsure whether I received correct treatment & 4.716 & .095 & 124.53 & 143.63 & 144.28 \\
\hline To follow-up what was said during my last visit & 15.664 & $<.001$ & 118.06 & 149.09 & 162.10 \\
\hline Involve my family members in my care. & 31.073 & $<.001$ & 115.44 & 129.11 & 177.40 \\
\hline
\end{tabular}

Contents of the medical record: Older adults considered that they understood most of the contents of the medical record to a similar extent than Young respondents (Table 3). The Elderly respondents differed significantly from the two other groups (Older adults vs. Elderly $\chi^{2}(2)=-$ 3.193, $p=.004$ and Young vs. Elderly $\chi^{2}(2)=2.801, p=.015$ ) by being the most confident group of respondents and the Older Adults the least confident.

Table 3: Contents of the medical record.

\begin{tabular}{|l|l|l|l|l|l|}
\hline & & & \multicolumn{3}{|c|}{ Mean Rank (Kruskal-Wallis) } \\
\hline Statements & Chi-Square & Sig. & $\begin{array}{l}\text { Young } \\
(\mathbf{n = 1 7 1})\end{array}$ & $\begin{array}{l}\text { Older Adults } \\
(\mathbf{n = 9 4 )}\end{array}$ & $\begin{array}{l}\text { Elderly } \\
\text { (n= 67) }\end{array}$ \\
\hline I understood most of the contents of the medical record. & 11.187 & .004 & 162.32 & 153.10 & 196.96 \\
\hline $\begin{array}{l}\text { I understood the parts of the medical record I was interested } \\
\text { in. }\end{array}$ & .491 & .782 & 147.41 & 143.14 & 152.48 \\
\hline
\end{tabular}


The groups differed to a certain extent in what they were inclined to do if they did not understand something in the record text (Table 4). There was no difference between Older Adults and Young respondents in their inclination to turn to a person with healthcare knowledge if they did not understand something in their record text whereas Elderly respondents were more likely to do that (Older Adults vs. Elderly $\chi^{2}(2)=2.800, p=.015$ and Young vs. Elderly $\chi^{2}(2)=3.022, p=.008$ ). In contrast, Older Adults were also less inclined to ask their family and friends $\left(\chi^{2}(2)=3.057\right.$, $\mathrm{p}=.007$ ), with no significant difference to Elderly respondents.

Table 4: What would you do if you did not understand something in the record text.

\begin{tabular}{|l|l|l|l|l|l|}
\hline & & & \multicolumn{2}{|c|}{ Mean Rank (Kruskal-Wallis) } \\
\hline Statements & Chi-Square & Sig. & $\begin{array}{l}\text { Young } \\
\text { (n=171) }\end{array}$ & $\begin{array}{l}\text { Older Adults } \\
\text { (n=94) }\end{array}$ & $\begin{array}{l}\text { Elderly } \\
\text { (n= 67) }\end{array}$ \\
\hline $\begin{array}{l}\text { What would you do if you did not understand something } \\
\text { in the record text }\end{array}$ & & & & \\
\hline $\begin{array}{l}\text { Ask a person with knowledge of healthcare (e.g., using 24/7 } \\
\text { telephone counseling service) }\end{array}$ & 10.067 & .007 & 138.21 & 136.97 & 178.84 \\
\hline Ask healthcare staff during my next visit. & 7.115 & .029 & 134.11 & 150.12 & 168.05 \\
\hline Ask healthcare staff using telephone. & 2.185 & .335 & 135.39 & 124.02 & 145.67 \\
\hline $\begin{array}{l}\text { Ask online the healthcare professionals I usually contact } \\
\text { (e.g., by secure e-mail) }\end{array}$ & 1.693 & .429 & 134.88 & 126.05 & 119.42 \\
\hline Ask a family member or a friend & 9.427 & .009 & 144.04 & 111.92 & 129.71 \\
\hline $\begin{array}{l}\text { Ask a healthcare professional I know personally, either in my } \\
\text { family or among my friends. }\end{array}$ & 5.140 & .077 & 143.30 & 121.13 & 125.00 \\
\hline Seek information by myself (e.g., in the Internet) & 2.857 & .240 & 144.31 & 126.79 & 140.98 \\
\hline $\begin{array}{l}\text { Use social media (e.g., discussion forum or Facebook) to get } \\
\text { help. }\end{array}$ & 4.646 & .098 & 137.02 & 126.31 & 112.24 \\
\hline $\begin{array}{l}\text { Ask someone to help me to translate the record from } \\
\text { Swedish to my own language. }\end{array}$ & .191 & .909 & 126.94 & 126.89 & 123.09 \\
\hline
\end{tabular}

The meaning of reading medical records (Table 5): Elderly respondents differed from Older Adults $\left(\chi^{2}(2)=2.839, \mathrm{p}=.014\right)$ and Young $\left(\chi^{2}(2)=4.268, \mathrm{p}<.001\right)$ respondents in their higher belief in that reading the medical record would improve communication with healthcare professionals. Similarly, they were more inclined to believe that reading the record would improve their understanding of their health or condition (Young vs. Elderly $\chi^{2}(2)=3.667, p<.001$, Older adults vs. Elderly $\left.\chi^{2}(2)=2.870, p=.004\right)$. In contrast, Young respondents were less inclined to believe that they would take better care of their health after reading their medical record (Young vs. Older Adults $\chi^{2}(2)=3.390, p=.002$, Young vs. Elderly $\left(\chi^{2}(2)=3.739, p<.001\right)$. In the belief that reading medical records would be necessary for the respondents to actively participate in their healthcare, the only significant difference was found between Young and Elderly, the Elderly respondents being more inclined to believe so $\left(\chi^{2}(2)=3.288, p=.003\right)$.

Older Adults differed from the two other groups in their lower inclination to keep a paper copy of their medical record for their own record even if the difference was significant only to Young respondents $\left(\chi^{2}(2)=2.571, \mathrm{p}=.030\right)$.

Table 5: What it means to you to be able to read you own medical record.

\begin{tabular}{|l|l|l|l|l|c|}
\hline & & & \multicolumn{2}{|c|}{ Mean Rank (Kruskal-Wallis) } \\
\hline Statements & Chi-Square & Sig. & $\begin{array}{l}\text { Young } \\
(\mathbf{n = 1 7 1})\end{array}$ & $\begin{array}{l}\text { Older Adults } \\
(\mathbf{n = 9 4 )}\end{array}$ & $\begin{array}{l}\text { Elderly } \\
(\mathbf{n}=\mathbf{6 7})\end{array}$ \\
\hline $\begin{array}{l}\text { What it means to you to be able to read you own medical } \\
\text { record }\end{array}$ & & & & & \\
\hline $\begin{array}{l}\text { It improves communication between me and the healthcare } \\
\text { professionals }\end{array}$ & 18.278 & $<.001$ & 133.27 & 148.40 & 190.28 \\
\hline It leads to the improvement of the care I receive. & 5.224 & .073 & 134.38 & 145.79 & 165.46 \\
\hline I will better understand my health/condition. & 13.588 & .001 & 140.30 & 147.20 & 189.40 \\
\hline I will take better care of my health. & 20.361 & $<.001$ & 123.32 & 159.81 & 175.85 \\
\hline
\end{tabular}




\begin{tabular}{|l|l|l|l|l|l|}
\hline It is necessary for me to actively participate in my healthcare. & 12.140 & .002 & 131.02 & 152.08 & 176.49 \\
\hline $\begin{array}{l}\text { I will keep the medical record for my own record (i.e. for } \\
\text { personal archival purposes). }\end{array}$ & 6.970 & .031 & 148.26 & 121.35 & 147.10 \\
\hline I am distrustful of the healthcare. & 2.204 & .332 & 129.31 & 143.80 & 129.71 \\
\hline
\end{tabular}

Online information and communication services (Tables 6, 7, and 8): Older Adults $\left(\chi^{2}(2)=2.594, p=.028\right)$ and Young respondents $\left(\chi^{2}(2)=2.939, p=.010\right)$ were less inclined than the Elderly to consider that a possibility to check laboratory results online would be helpful for them. In contrast, Young respondents were more likely to see the possibility to manage services for their children as useful (Young vs. Elderly $\chi^{2}(2)=3.764, p<.001$, Older Adults vs. Young $\left.\chi^{2}(2)=3.267, \mathrm{p}=.003\right)$. Using the service for managing the same information for elderly relatives was perceived as significantly more useful by Younger respondents (Young vs. Elderly $\chi^{2}(2)=2.632, p=.025$ ) with no difference between Elderly and Older Adults. Older Adults were least inclined to believe that the service would be useful for reading letters of referral, with a significant difference between Older Adults and Elderly respondents $\left(\chi^{2}(2)=2.649, p=.024\right)$.

Table 6: Access to services based on information found in medical record.

\begin{tabular}{|c|c|c|c|c|c|}
\hline & & & \multicolumn{3}{|c|}{ Mean Rank (Kruskal-Wallis) } \\
\hline & Chi-Square & Sig. & $\begin{array}{l}\text { Young } \\
(\mathrm{n}=171)\end{array}$ & $\begin{array}{l}\text { Older Adults } \\
(\mathrm{n}=94)\end{array}$ & $\begin{array}{l}\text { Elderly } \\
(\mathrm{n}=67)\end{array}$ \\
\hline \multicolumn{6}{|l|}{$\begin{array}{l}\text { It would be useful to have an access to following } \\
\text { information services based on the information found in } \\
\text { your medical record: }\end{array}$} \\
\hline $\begin{array}{l}\text { Letters of referral (contents and how they are processed by } \\
\text { the care providers) }\end{array}$ & 7.062 & .029 & 156.84 & 141.35 & 177.05 \\
\hline List of all my medications & .932 & .628 & 160.70 & 151.34 & 154.58 \\
\hline Overview of my vaccinations & .176 & .916 & 154.64 & 153.59 & 158.53 \\
\hline Test results directly after tests have been conducted & 9.358 & .009 & 155.17 & 155.89 & 188.05 \\
\hline $\begin{array}{l}\text { Overview of all contacts with healthcare together with a } \\
\text { possibility to read the entire medical record }\end{array}$ & 5.485 & .064 & 160.13 & 141.59 & 170.87 \\
\hline Possibility to manage and order medical certificates & 2.628 & .269 & 160.96 & 147.05 & 145.34 \\
\hline Possibility to report errors in my medical record. & 2.588 & .274 & 153.46 & 149.80 & 171.59 \\
\hline Possibility to write own comments in the text of the record. & 1.160 & .560 & 149.72 & 147.10 & 163.04 \\
\hline $\begin{array}{l}\text { Possibility to provide information of my own health (e.g., to } \\
\text { submit a health declaration [obligatory in Sweden] before } \\
\text { each visit). }\end{array}$ & .138 & .933 & 153.62 & 152.51 & 148.64 \\
\hline $\begin{array}{l}\text { Possibility to provide information (e.g., by reporting self-test } \\
\text { results taken at home) }\end{array}$ & .654 & .721 & 150.21 & 156.30 & 144.36 \\
\hline $\begin{array}{l}\text { Possibility to contact healthcare online and to ask questions } \\
\text { of the contents of my medical record. }\end{array}$ & 4.728 & .094 & 157.69 & 140.23 & 170.60 \\
\hline $\begin{array}{l}\text { Possibility to block parts of my medical record from other } \\
\text { healthcare staff (who have not written them). }\end{array}$ & 2.605 & .272 & 159.18 & 141.35 & 155.72 \\
\hline $\begin{array}{l}\text { Possibility to see which healthcare units and categories of } \\
\text { staff have read and written in my medical record. }\end{array}$ & .921 & .631 & 154.89 & 152.68 & 165.25 \\
\hline $\begin{array}{l}\text { Possibility to manage services for my children (e.g., letters of } \\
\text { referral, vaccinations, and medication lists). }\end{array}$ & 19.693 & 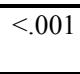 & 164.92 & 130.73 & 114.21 \\
\hline $\begin{array}{l}\text { Possibility to manage services for elderly family members } \\
\text { (e.g., letters of referral, vaccinations, and medication lists). }\end{array}$ & 3.626 & .163 & 154.29 & 136.99 & 135.97 \\
\hline $\begin{array}{l}\text { Possibility to manage services for other persons (e.g., letters } \\
\text { of referral, vaccinations, and medication lists). }\end{array}$ & 6.975 & .031 & 152.38 & 142.40 & 115.55 \\
\hline
\end{tabular}

Older Adults and Elderly respondents were more inclined to believe that the service can be too difficult to use (Young vs. Elderly $\chi^{2}(2)=2.909, p=.011$, Young vs. Older Adults $\chi^{2}(2)=3.737$, $\mathrm{p}<.001)$. The Elderly respondents were more inclined to only talk with healthcare staff and not to use such a service at all, in comparison to Young respondents $\left(\chi^{2}(2)=3.346, p=.002\right)$ or Older Adults, however with a significant difference only to the first mentioned group.

Table 7: General questions of an online access service to own medical records. 


\begin{tabular}{|l|l|l|l|l|l|}
\hline & & & \multicolumn{2}{|c|}{ Mean Rank (Kruskal-Wallis) } \\
\hline Statements & Chi-Square & Sig. & $\begin{array}{l}\text { Young } \\
\text { (n= 171) }\end{array}$ & $\begin{array}{l}\text { Older Adults } \\
\text { (n=94) }\end{array}$ & $\begin{array}{l}\text { Elderly } \\
\text { (n= 67) }\end{array}$ \\
\hline $\begin{array}{l}\text { General questions of an online access service to own } \\
\text { medical records }\end{array}$ & & & & & 166.00 \\
\hline $\begin{array}{l}\text { It is a very good idea to be able to read medical records } \\
\text { online (similarly to that how I can manage my bank accounts } \\
\text { online). }\end{array}$ & 1.082 & .582 & 171.97 & 160.34 & \\
\hline I am generally worried of the security of the service. & .535 & .765 & 151.83 & 155.09 & 161.62 \\
\hline $\begin{array}{l}\text { I am worried that the medical records are not managed } \\
\text { securely enough in the healthcare information systems if they } \\
\text { can be read online. }\end{array}$ & .895 & .639 & 150.23 & 159.53 & 159.78 \\
\hline I am worried that the service will too difficult to use. & 17.787 & $<.001$ & 131.40 & 172.42 & 171.10 \\
\hline $\begin{array}{l}\text { I am not so interested in my medical record that I would read } \\
\text { it online. }\end{array}$ & .202 & .904 & 144.86 & 147.41 & 140.62 \\
\hline $\begin{array}{l}\text { I do not want to read my medical record online, only } \\
\text { personally discuss with healthcare professionals. }\end{array}$ & 12.802 & .002 & 133.54 & 156.74 & 177.06 \\
\hline Statements & & & & & 136.05 \\
\hline I like to communicate with medical doctors using e-mail. & 13.045 & .001 & 177.43 & 135 & 155.38 \\
\hline $\begin{array}{l}\text { Internet is a very important source of health information for } \\
\text { me. }\end{array}$ & 8.839 & .012 & 173.87 & 141.53 & 149.85 \\
\hline $\begin{array}{l}\text { I use a lot of social media services on health information } \\
\text { matters (e.g., discussion forum, Facebook, and Twitter). }\end{array}$ & 6.478 & .039 & 165.88 & 144.13 & 146.01 \\
\hline
\end{tabular}

Elderly respondents were less interested in reading their medical record online but instead personally discuss with healthcare professionals (Table 7) than Older Adults $\left(\chi^{2}(2)=3.193\right.$, $\mathrm{p}=.001)$ or Young respondents $\left(\chi^{2}(2)=2.801, \mathrm{p}=.015\right)$. In contrast, the Young respondents were most interested in communicating with their medical doctor by email, with a significant difference between them and Older Adults $\left(\chi^{2}(2)=3.564, p<.001\right)$, which was somewhat surprisingly the least interested group in this comparison. Similarly, Internet was a more important information source for them than for the two other groups (significant difference between Young and Older Adults $\left.\chi^{2}(2)=2.810, p=.015\right)$. Similarly, the Young respondents were most inclined to use social media for health information seeking (overall difference between groups was significant, whereas no significant differences in group-wise comparisons).

Table 8: Statements and questions about health information behaviour analysed using ChiSquare tests.

\begin{tabular}{|c|c|c|c|c|c|c|c|c|}
\hline \multirow{3}{*}{ Statements } & \multirow{3}{*}{ Chi-Square } & \multirow{3}{*}{ Sig. } & \multicolumn{6}{|c|}{ Standardised residuals (Chi-Square)* } \\
\hline & & & \multicolumn{2}{|c|}{$\begin{array}{c}\text { Young } \\
(\mathrm{n}=171)\end{array}$} & \multicolumn{2}{|c|}{$\begin{array}{c}\text { Older Adults } \\
(\mathrm{n}=94)\end{array}$} & \multicolumn{2}{|c|}{$\begin{array}{l}\text { EIderly } \\
(n=67)\end{array}$} \\
\hline & & & Yes & No & Yes & No & Yes & No \\
\hline $\begin{array}{l}\text { I have searched health information in the Internet during the last } \\
\text { week (Yes/No) }\end{array}$ & 17.203 & $<.001$ & 2.2 & -1.8 & -1.2 & 1.0 & -2.0 & 1.7 \\
\hline I have read medical literature during the last year (Yes/No) & 2.956 & .228 & .8 & -.4 & -1.3 & .7 & .3 & -.2 \\
\hline $\begin{array}{l}\text { Have your physician ever recommended you to seek health } \\
\text { information on the Internet? (Yes/No) }\end{array}$ & 10.132 & .006 & 2.1 & -.6 & -1.5 & .4 & -1.6 & .5 \\
\hline Are you a member in a patient association? & 11.393 & .003 & -2.1 & .8 & 1.1 & -.4 & 2.1 & -.8 \\
\hline
\end{tabular}

\section{Discussion}

The aim of this study is to map the preferences and motivations of older adults ordering a copy of their medical record, and using medical records based e-health and information services in the future. This relates to their health information behaviour and also to their personal health information mastering. The analysis revealed several significant differences but also some similarities between the groups of Younger, Older Adults and Elderly respondents. 


\subsection{Differences between age groups}

\subsubsection{Main differences between Young and Older adults}

When compared to the other age groups, older adults were more likely to have ordered a copy of their medical record to get an overview of their health or condition or to follow up what was said during their last visit to healthcare. They were more inclined to believe that they would take better care of their health after reading their medical record but also that an online access service for medical records could be too difficult to use. Furthermore, they were less interested in communication with their medical doctor by e-mail. Yet, they had searched health information in the Internet during the last week more likely than Young.

\subsubsection{Main differences between Older adults and Elderly}

Surprisingly, the Older adults were less confident that they understood most of the content of their medical records. They were less inclined to consider that a possibility to check laboratory results online would be helpful for them. Moreover, they were less likely to turn to a person with healthcare knowledge or to their family or friends if they did not understand something in the medical record text. Older adults were more interested in reading their medical record online than Elderly.

\subsubsection{Similarities between the Young, Older adults and Elderly}

In addition to the detected differences between the groups, some aspects where no difference was detected deserve specific attention. None of the groups was generally more or less likely to order a copy of their medical record to check or verify details in the text to see if they had received correct care, or to involve their family members in their care. There were no significant differences in concerns regarding the security aspects of future online service for reading own medical records, or interest in using such a service. In general, the respondents were moderately worried of the security of such a service and somewhat more worried that the medical records are not managed securely enough in healthcare information systems if they can be read online. Even the expectations of the usefulness of many proposed medical records based online services did not significantly differ between the three groups (e.g. manage and order medical certificates, report errors, write comments or provide information in the medical record, to control and follow who accesses the medical record, manage services for elderly family members, or others). Finally, it may be noted that there were no significant differences in how the different groups were reading medical literature or subscribing to health magazines.

As could be expected, in most cases the Older Adults formed a middle group with attitudes and views that fell between those in the two other groups. They were more concerned and interested in medical record information, and prepared to act on the basis of that information they read than younger respondents, but in comparison to the elderly, they seemed to lack a continuous contact with healthcare.

The differences can be partially explained by the typical life situations in the groups. Older individuals have seldom young children in their custodianship whereas they are more likely to be responsible for their elderly relatives or family members. In some cases, the Older Adults do, however, position themselves differently than other respondents. Even if the difference is statistically insignificant, Older Adults indicated that they think about their health more than others although the Elderly were the most worried about their health and the Young the most inclined to believe that their health was very good. Together with the similarly indicative finding 
that the Older Adults were least inclined to see many online information and communication services as useful (Tables 4, 6, 7) and did not order medical record for their own record, it may be surmised that Older Adults are in the phase of life when people have a relatively established and stable pattern of information behaviour and are less likely to need and ask others for additional information (Table 4). Their use and immediate need of health services is still rather low but they have already started to think about their health. In this sense, the group could be expected to benefit from services and information that would support them in their ponderings.

Also, certain generational issues relating to lower levels of digital and computer literacy and less online-centred information behaviour of older people can explain the relatively higher concerns of the difficulty of using e-health services and preference of online health information and communication. The finding that the differences in social media use were not statistically significant between the age groups was interesting even if the ranks showed expected differences, Younger respondents being the most and Elderly the least active users.

The findings give further support to earlier observations of how older and elderly individuals differ from other age groups and, as Johnson (2014) underlines, the importance to focus on actual health information behaviours of particular individuals and groups instead of making assumptions based on ideal types. For instance, the findings of Eriksson-Backa (2011) that at the retirement age, people need health information primarily when they get ill can be related to the indications of the lower general interest of health information services. The results about perceived usefulness of health information for improving communication with healthcare professionals and for being able to take better care of one's own health are similar to those of Taha et al. (2009) and Medlock et al. (2015), even if the major differences were between the Elderly and others, not with Older Adults. Like in earlier studies, healthcare providers are an important source of health information for Older Adults (e.g., Renahy et al. 2008; Taha et al. 2009; Eriksson-Backa, 2013; Medlock et al., 2015) whereas they were the least likely group to use family and friends as a source for additional information if they did not understand something in their medical record or to use Internet for the same purpose. In this respect, they differ from the elderly persons in the studies by Niemelä (2006) and Zickuhr and Madden (2012), who found that friends and family, as well as the Internet, were fairly important health information sources. Furthermore, similarly to the findings of Woods et al. (2013), the older patients were the most inclined to consider that reading medical records would have a positive impact on communication with healthcare providers, knowledge of their health, improved self-care, and greater participation but as Table 5 shows, the difference becomes significant first between Older Adults and the Elderly.

Although earlier studies (Enwald et al., 2017) show that older people have difficulties in understanding and accepting health information, the present findings show that this does not necessarily apply to medical records, i.e. health information about themselves. Similarly, even if it was possible to sense a relative digital divide between the older and younger respondents (cf.; Gilleard \& Higgs, 2008; Yan, 2010; Eriksson-Backa, 2013; Kontos et al., 2014), it split the respondents somewhat unevenly. In general, Young respondents were more likely to use online sources for health information seeking (Tables 7 and 8) than Older Adults or Elderly, and were least concerned about the security and difficulty of the service. This is in accordance with previous studies (e.g., Gilleard \& Higgs, 2008; Ek \& Niemelä, 2010; Yan, 2010; Kontos et al. 2014). Yet, the lack of the perceived importance of communicating with medical personnel using email, use of social media services and the importance of Internet as a source for health information among Older Adults shows that the Elderly people can be more active users of digital 
sources, apparently, because of their stronger need for information (cf., Niemelä, 2006, 121; Gordon \& Hornbrook, 2016).

\subsection{Implications for the provision and management of health information for older adults}

The results show that medical records and health information have potential to influence patient engagement and informedness in all age categories. In this respect, the findings confirm earlier, so far somewhat inconclusive evidence, that providing access to medical records and health information based on the contents of the medical record can be a successful strategy for informing patients. When drawing this conclusion, it is important to consider the likely bias in the analysed material that the respondents do not represent the whole population and are more inclined to believe that reading medical records is beneficial. In the material, it seems that especially for Older Adults the medical record was perceived as a complement and an instrument to support personal communication with healthcare personnel. Elderly people seemed to have a stronger belief in the practical benefits of reading the information whereas the younger were less likely to see the medical record as a significant source of health information or as a contributor to a better healthcare. In a general sense, the findings can be seen as an indication of older adulthood as a transitory stage of life when the need of health information increases and engagement with health changes. In contrast to general interest across age groups and earlier findings of, for instance, Hoerbst et al. (2010), the Older Adults perceived the usefulness of medical record for health information management rather low (Table 5 and 6). On the other hand, the worries about the difficulty of using online information and health services seem to go hand in hand with the likelihood of using online information (Tables 7 and 8) and both seem to be lowest in the group of Older Adults. This particular group seems an especially significant target for interventions for increasing health information literacy and patient engagement, and development and deployment of access measures (e.g. patient portals) that are tailored them. It seems plausible to expect that the risk of assuming such health information behaviours, which are detrimental (or less than optimal) from the healthcare perspective but that make sense from the perspective of the individual (Johnson, 2014) is significant in this group with both health and health behaviour, and health information behaviour that are in a stage of transition. With Elderly, it seems plausible that the more positive attitudes are driven by increased needs. In practice, because of the lack of immediate needs, the suggestion of Harris et al. (2002) to focus on easy availability and understandability of health information for older adults is supported by the present findings. Here, both technical (e.g. tailored search systems) and social measures (e.g. communication, promotion of engagement and literacy) can be useful.

It seems likely that in the long run, the most significant theoretical and practical implication of the results relate to the different life situations of the respondents. Getting an overview of a health condition, to follow up what was said during the last visit to healthcare, the need of involving family members in their care, caring for elderly relatives (than for their children) and probably to a certain degree, asking help from relatives and family members are likely to be traits that persist. Also, the fact that Younger were in better self-perceived health than Older Adults or Elderly with Elderly being more likely to have chronic conditions than the two other groups of respondents suggest of a pattern that is likely to persist and increase the significance of health information in the older age groups even in the future.

In contrast, the online versus offline preferences, or technical and security concerns are likely to be of less concern when currently younger respondents become older adults and older adults become elderly. Even if the earlier research has shown differences between younger and older 
age groups in their technology preferences (e.g., Kontos et al., 2014; Asla \& Williamson, 2015; Nikou, 2015) that are similar to the ones in the current findings, the fact that the differences, for instance, in social media use are not significant in the analysed material can be interpreted from the perspective of ecological and life-course oriented models of ageing as indicators of the potentially decreasing significance of these issues with currently available technologies and modalities of information delivery. On the basis of the life-course perspective (Fobes \& McCullen, 2016), it is believable that in addition to communication preferences, also the level of engagement and competences of future older adults build on their earlier habits and preferences. It would be important to support positive interest in the transition from younger age to being an older adult, and again, as the current results suggest, from the relative plateau of older adulthood to the later age. This perspective does not negate the earlier urges for an increased focus on the health information behaviour of the oldest old (Asla \& Williamson, 2015), but underlines both the theoretical and practical importance of considering the longue durée of how and when information behaviour changes, and how to proactively support effective information use as a part of successful ageing. Even if the information science literature has been acknowledged the volatility of information behaviour, there is a need to focus more changes not only towards the end of the life but in different stages of life. There is no reason to believe that a focus on older adults would make older people to act according to idealised models of health and health information behaviour (Johnson, 2014) but a more careful consideration of individual preferences in different life stages could open up for both understanding current and anticipating future information preferences and behaviours of patients.

When considering the findings, it is important to note that the analysed material has limitations. A major limitation of the study is that the categorising of the patients has been based on selfreported physical age, not the cognitive age of the patients. Considering that this has been found to be have an impact on information behaviour (Sanchiz et al., 2017), it is probable that from the cognitive perspective, some of the respondents have been categorised in an incorrect age group in this sense and the significance of the findings between the groups in the study is lower than it could be. On the population level, there were some differences between the studied group and the general Swedish population (Statistics Sweden, 2012; www.scb.se). In comparison to the Swedish general population, females were overrepresented in the survey sample $(74 \%$ versus $50 \%)$. The respondents were more likely to have Internet access at home $(92 \%$ in the survey versus $84 \%$ reported by Weibull et al., 2012). Similarly to the surveyed sample in $2012,84 \%$ of Swedes had secondary or upper secondary level education in 2011 (Statistics Sweden, 2012). All respondents had ordered a copy of their medical record, which differentiates them from the general population. In the studied Swedish county, approximately $3.6 \%$ of the population $(11,000$ patients of 300,$000 ; 3.6 \%$ ) have annually ordered a copy of their medical record in the 2000 (L. Lyttkens, personal communication, August 15, 2013). This evinces of their interest in health, medical records, and particular types of healthcare services. It is obvious that the findings cannot be generalised to the entire population of the county or the country as a whole. Yet, the results can be considered to give indications of the preferences of a group of people with a specific, at least temporary, interest or need in health information.

\section{Conclusions}

This research relates to the use of medical records-based health information by different age groups of citizens, from young to the elderly. It attempted to (1) understand how citizens of different ages (young, older adult, and the elderly) differ in terms of their preferences and motivations for using this information. It also aimed at (2) understanding the implications that 
differences in these preferences and motivations among the age groups hold for the provision of healthcare information for citizens of varying ages.

The results regarding (1) are consistent with prior research on several areas related to the older adults group and the elderly group. Namely, the older adults reported little interest in online medical records-based health information and were less eager to discuss such information with family and friends than other age groups. The elderly, on the other hand, have been identified as being interested in health information to deal with personal illness. They consider health information as a tool to improve communication with healthcare professionals. Related to (1), this research adds to prior research on the following point. While prior literature has showed that the elderly had difficulties to accept and understand health information, our results show this is not necessarily the case with medical records (i.e. health information about oneself). The elderly had some reservations to accessing online health records, but were more confident than older adults in understanding health information.

Regarding (2), the results agree with prior research on the potential usefulness of online medicalrecords -based health information as a channel to inform citizens. However, our results add to prior research with the finding that specific provision strategies, methods and technologies (e.g. customised search facilities) may be necessary to match the needs and motivations of each of the three age groups. The results do not indicate an obvious linear relationship between age and motivation to use online health information. Older adulthood seems to represent a transitory period between younger adulthood and becoming older old but with specific needs and preferences related to that particular stage of life. For example, the older adult age group seems to be most challenging in terms of empowerment to search and use online health information, because they are the least confident and least motivated to use online health information. Interventions to increase the capability of this group to adopt online health information should be a priority.

\section{Acknowledgements}

The data analysed in the study was collected as a part of the Swedish research project Deployment of Online Medical records and E-health services (DOME) financed by VINNOVA, the Swedish Governmental Agency for Innovation Systems. For the data collection, the DOME project has collaborated with SUSTAINS, a project co-funded under the ICT Policy Support Programme (ICT PSP) as part of the Competitiveness and Innovation Framework Programme of the European Commission. The analysis was conducted as a part of the Academy of Finland funded research project Taking Health Information Behaviour into Account: implications of a neglected element for successful implementation of consumer health technologies on older adults (HIBA) and as a part of the work of the Swedish DOME research consortium for e-health research. This work has also received funding from FORTE - the Swedish Research Council for Health, Working Life and Welfare supports "PACESS" (2016-00623).

\section{References}

Alpi, K.M. \& Bibel, B.M. (2004). Meeting the health information needs of diverse populations. Library Trends 53(2), 268-282.

Ammenwerth, E., Schnell-Inderst, P. \& Hoerbst, A. (2012) The impact of electronic patient portals on patient care: a systematic review of controlled trials. Journal of Medical Internet Research 14(6), e162. doi: 10.2196/jmir.2238.http://www.jmir.org/2012/6/e162/ 
Ancker, J.S., Witteman, H.O., Hafeez, B., Provencher, T., Van de Graaf, M. \& Wei, E. (2015). The invisible work of personal health information management among people with multiple chronic conditions: Qualitative interview study among patients and providers. Journal of Medical Internet Research, 17(6), e137. https:/www.ncbi.nlm.nih.gov/pmc/articles/PMC4526906/

Asla, T. M. \& Williamson, K. (2015). Unexplored territory: information behaviour in the fourth age. Proceedings of ISIC, the Information Behaviour Conference, Leeds, 2-5 September, 2014: Part 2, (paper isic32). Retrieved from http://InformationR.net/ir/20-1/isic2/isic32.html

Attfield S J, Adams A, Blandford A. (2006). Patient information needs: pre- and postconsultation. Health Informatics Journal 12(2): 165-177.

Berens, E.M., Vogt, D., Messer, M., Hurrelmann, K. \& Schaeffer, D. (2016). Health literacy among different age groups in Germany: results of a cross-sectional survey. BMC Public Health (2016), 16:1151 DOI 10.1186/s12889-016-3810-6

Caiata-Zufferey, M., Abraham, A., Sommerhalder, K. \& Schulz, P.J. (2010). Online health information seeking in the context of the medical consultation in Switzerland. Qualitative Health Research 20(8), 1050-1061.

Case, D. O. \& Given, L. M. (2016). Looking for information : a survey of research on information seeking, needs, and behavior. Bingley: Emerald.

Chin, J.; Payne, B.; Gao, X.; Conner-Garcia, T.; Graumlich, J. F.; Murray, M. D.; Morrow, D. G. \& Stine-Morrow, E. A. L. (2015). Memory and comprehension for health information among older adults: Distinguishing the effects of domain-general and domain-specific knowledge. Memory, 23(4), 577-589.

Clarke, M. A.; Moore, J. L.; Steege, L. M.; Koopman, R. J.; Belden, J. L.; Canfield, S. M.; Meadows, S. E.; Elliott, S. G. \& Kim, M. S. (2016). Health information needs, sources, and barriers of primary care patients to achieve patient-centered care: A literature review. Health Informatics Journal, 22(4), 992-1016.

Personal Health Working Group (2003). Connecting for Health - A Public Private Collaboration. Final Report. 2003. Available at: https:/www.markle.org/publications/1429-personal-healthworking-group-final-report

Darking, M.; Anson, R.; Bravo, F.; Davis, J.; Flowers, S.; Gillingham, E.; Goldberg, L.; Helliwell, P.; Henwood, F.; Hudson, C.; Latimer, S.; Lowes, P. \& Stirling, I. (2014). Practicecentred evaluation and the privileging of care in health information technology evaluation. $B M C$ Health Services Research, 2014, 14(1), 243.

Dong, L. (2015). Taking the long view of medical records preservation and archives. Journal of Documentation, 71(2), 387-400.

Ek, S. \& Heinström, J. (2011). Monitoring or avoiding health information - the relation to inner inclination and health status. Health Information and Libraries Journal, 28 (3), 200-209. doi: 10.1111/j.1471-1842.2011.00947.x 
Ek, S. \& Niemelä, R. (2010). 'Onko internetistä tullut suomalaisten tärkein terveystiedonlähde? Deskriptiivistä tutkimustietoa vuosilta 2001 ja 2009' (Has the Internet Become the Finns’ Most Important Source of Health Information? Descriptive Data from the Years 2001 and 2009). Informaatiotutkimus 29(4). Available at: https://journal.fi/inf/article/view/3856

Ekendahl, M. (2011). En modell för att hantera journaluppgifter på internet för patienter [Model for managing medical record informtion for patients on the Internet]. Technical report, INERA, Stockholm.

Enwald H, Kangas M, Keränen N, Immonen M, Similä H, Jämsä T \& Korpelainen R (2017) Health information behaviour, attitudes towards health information and motivating factors for encouraging physical activity among older people: differences by sex and age In Proceedings of ISIC, the Information Behaviour Conference, Zadar, Croatia, 20-23 September, 2016: Part 2. Information Research, 22(1), paper isic1623. http://www.informationr.net/ir/221/isic/isic1623.html

Eriksson-Backa, K. (2011). Health information behaviour among retired Finns with either normal weight or obesity. In: Peter A. Bath, Tobias Mettler, Dimitri A. Raptis, Barbara A. Sen (Eds.) Proceedings of the 15th International Symposium for Health Information Management Research - ISHIMR 2011. Zürich, Switzerland, 8th to 9th September, 2011, pp. 259-269.

Eriksson-Backa, K.; Ek, S.; Niemelä, R. \& Huotari, M.-L. (2012). Health information literacy in everyday life: A study of Finns aged 65--79 years. Health Informatics Journal, 18(2), 83-94.

Eriksson-Backa, K. (2013). The role of online health information in the lives of Finns aged 65 to 79 years. International Journal of Networking and Virtual Organisations 13(1), 5-23.

Eriksson-Backa, K. \& Ek, S (2015). Health information literacy and communication in healthcare contexts: a study of older Finnish adults. In: Bath, Peter A., Spring, Hannah, Sen, Barbara (eds.) The Seventeenth International Symposium for Health Information Management Research (iSHIMR); 2015 24-26 June, York, UK, 2015, proceedings, pp 77-91.

European Commission (2017). eHealth: Digital Single Market. Available at: https://ec.europa.eu/digital-single-market/en/policies/ehealth

Fobes, C. \& McCullen, M. M. (2016). Life Course Perspective. In Shehan, C. L. (Ed.) Encyclopedia of Family Studies, The Wiley Blackwell Encyclopedia of Family Studies, Wiley, 16.

Fowles, J. B., Kind, A. C., Craft, C., Kind, E. A., Mandel, J. L. \& Adlis, S. (2004). Patients' interest in reading their medical record: relation with clinical and sociodemographic characteristics and patients' approach to health care. Archives of Internal Medicine 164(7), 793800 .

Gilleard, C. \& Higgs, P. (2008). Internet use and the digital divide in the English longitudinal study of ageing. European Journal of Ageing 5(3), 233-239. 
Gordon, N. P. \& Hornbrook, M. C. (2016). Differences in Access to and Preferences for Using Patient Portals and Other eHealth Technologies Based on Race, Ethnicity, and Age: A Database and Survey Study of Seniors in a Large Health Plan. Journal of Medical Internet Research, 18(3), e50

Graffigna, G., Barello, S., Riva, G. \& Bosio, A.C. (2014). Patient engagement: the key to redesign the exchange between the demand and supply for healthcare in the era of active ageing. In: G Riva, PA Marsan \& C Grassi (eds) Active Ageing and Healthy Living, In Studies of Health Technology and Informatics 203, IOS Press, 85-95.

Grünloh, C.; Cajander, Å. \& Myreteg, G. (2016). "The Record is Our Work Tool!"-Physicians' Framing of a Patient Portal in Sweden. Journal of Medical Internet Research, 2016, 18, e167.

Gruman, J., Rovner, M. H., French, M. E., Jeffress, D., Sofaer, S., \& Shaller, D. (2010). From patient education to patient engagement: implications for the field of patient education. Patient Education and Counseling 78, 350-356. doi: 10.1016/j.pec.2010.02.002

Gutierrez, N., Kindratt, T.B., Pagels, P., Foster B. \& Gimpel N.E. (2014) Health Literacy, Health Information Seeking Behaviors and Internet Use Among Patients Attending a Private and Public Clinic in the Same Geographic Area Journal of Community Health (2014) 39 (1): 83-89. https://doi.org/10.1007/s10900-013-9742-5

Harris, M., Bayer, A. \& Tadd, W. (2002). Addressing the information needs of older patients. Reviews in Clinical Gerontology 12(1), 5-11.

Hartzler, A. L.; Osterhage, K.; Demiris, G.; Phelan, E. A.; Thielke, S. M. \& Turner, A. M. (2017). Understanding views on everyday use of personal health information: Insights from community dwelling older adults. Informatics for Health and Social Care, 1-14. http://dx.doi.org/10.1080/17538157.2017.1297815

Henwood, F., Wyatt, S., Hart, A. \& Smith, J. (2003). 'Ignorance is bliss sometimes': constraints on the emergence of the 'informed patient' in the changing landscapes of health information. Sociology of Health \& Illness 25(6), 589-607.

Hibbard, J. H., Stockard, J., Mahoney, E. R., and Tusler, M. (2004). Development of the Patient Activation Measure (PAM): conceptualizing and measuring activation in patients and consumers. Health Serv. Res. 39(4 Pt. 1), 1005-1026.

Hibbard, J. H. \& Greene, J. (2013). What The Evidence Shows About Patient Activation: Better Health Outcomes And Care Experiences; Fewer Data On Costs. Health Affairs, 32(2), 203-206.

Hibbard, J. H.; Greene, J. \& Overton, V. (2013). Patients with lower activation associated with higher costs; delivery systems should know their patients scores. Health Affairs 32(2), 207-214.

Hirvonen, N., Ek, S., Niemelä, R., Pyky, R., Ahola, R., Korpelainen, R., Huotari, M.-L. (2016). Everyday health information literacy in relation to health behaviour and physical fitness: a population-based study among young men. Library \& Information Science Research 38(4), 308318. https://doi.org/10.1016/j.lisr.2016.11.013 
Hoerbst, A., Kohl, C. D., Knaup, P. \& Ammenwerth, E. (2010). Attitudes and behaviors related to the introduction of electronic health records among Austrian and German citizens. International Journal of Medical Informatics 79(2), 81-89.

Huvila, I.; Cajander, Å.; Daniels, M. \& Åhlfeldt, R.-M. (2015) Patients’ Perceptions of their Medical Records from Different Subject Positions. JASIST, 66(12), 2456-2470.

Huvila, I.; Daniels, M.; Cajander, Å. \& Åhlfeldt, R.-M. (2016). Patients reading their medical records: differences in experiences and attitudes between regular and inexperienced readers. Information Research, 21(1).

Huvila, I.; Ek, S.; Enwald, H.; Eriksson-Backa, K.; Hirvonen, N. \& Känsäkoski, H. (2016). Taking Health Information Behaviour into Account in the design of e-health services. Finnish Journal of eHealth and eWelfare, 8(4), 153-163.

Irizarry T, DeVito Dadds A \& Curran CR (2015) Patient portals and patient engagement: A state of the science review. Journal of Medical Internet Review 17(6), 3148. Available at:

https://www.ncbi.nlm.nih.gov/pmc/articles/PMC4526960/

Johnson, J. D. \& Case, D. O. (2012). Health information seeking. New York: Peter Lang.

Johnson J. D. (2014) Health-related information seeking: Is it worth it? Information Processing \& Management, 50(5), 708-717.

Jung, M. (2014). Associations of self-rated health and socioeconomic status with information seeking and avoiding among post-treatment cancer patients. Asian Pacific Journal Cancer Prevention, 15(5), 2231-2238.

Kaphingst, K.A., Goodman, M.S., MacMillan, W.D., Carpenter, C.R. \& Griffey R.T. (2014). Effect of cognitive dysfunction on the relationship between age and health literacy. Patient Education and Counseling, 95(2), 218-225. https://doi.org/10.1016/j.pec.2014.02.005

Karnam, S. \& Raghavendra, P. (2017). Hybrid doctors: The need risen from informed patients. Journal of Clinical and Diagnostic Research, 11(2), ZI01-ZI04.

Kontos, E., Blake, K.D., Chou, W.Y.S. \& Prestin, A. (2014). Predictors of eHealth Usage: Insights on The Digital Divide From the Health Information National Trends Survey 2012. Journal of Medical Internet Research, 16(7):e172 DOI: 10.2196/jmir.3117

Li, N., Orrange, S., Kravitz, R.L. \& Bell, R.A. (2014). Reasons for and predictors of patients' online health information seeking following a medical appointment. Family Practice, 31(5), 550556, https://doi.org/10.1093/fampra/cmu034

Lloyd, A.; Bonner, A. \& Dawson-Rose, C. (2014). The health information practices of people living with chronic health conditions: Implications for health literacy. Journal of Librarianship and Information Science, 46(3), 207-216

de Lusignan, S.; Mold, F.; Sheikh, A.; Majeed, A.; Wyatt, J. C.; Quinn, T.; Cavill, M.; Gronlund, T. A.; Franco, C.; Chauhan, U.; Blakey, H.; Kataria, N.; Barker, F.; Ellis, B.; Koczan, P.; 
Arvanitis, T. N.; McCarthy, M.; Jones, S. \& Rafi, I. (2014). Patients' online access to their electronic health records and linked online services: a systematic interpretative review, $B M J$ Open 4:e06021.

Lustria, M. L. A., Smith, S. A., \& Hinnant, C. C. (2011). Exploring digital divides: An examination of eHealth technology use in health information seeking, communication and personal health information management in the USA. Health Informatics Journal, 17(3), 224243.

McColl-Kennedy, J.R., Snyder, H., Elg, M., Witell, L., Helkkula, A., Hogan, J.H. \& Anderson, L. (2017) The changing role of the health care consumer: review, synthesis and research agenda. Journal of Service Management, 28(1), 2-33.

McNamara, M.; Arnold, C.; Sarma, K.; Aberle, D.; Garon, E. \& Bui, A. A. T. (2015). Patient portal preferences: Perspectives on imaging information. JASIST, 66(8), 1606-1615.

Medlock, S., Eslami, S., Askari, M., Arts, D.L., Sent, D., de Rooij, S.E. \& Abu-Hanna, A (2015). Health Information-Seeking Behavior of Seniors Who Use the Internet: A Survey. Journal of Medical Internet Research 2015 Jan; 17(1): e10. doi: 10.2196/jmir.3749

Mockford, C.; Staniszewska, S.; Griffiths, F. \& Herron-Marx, S. (2012). The impact of patient and public involvement on UK NHS health care: a systematic review. International Journal for Quality in Health Care, 24(1), 28-38.

Nease, R. F., Frazee, S. G., Zarin, L. \& Miller, S. B. (2013). Choice architecture is a better strategy than engaging patients to spur behavior change. Health Affairs 32(2), 232-241

Niemelä R. (2006) Ikääntyneiden informaatiokäyttäytyminen. Laadullinen tutkimus arkielämän informaatiokäytännöistä ja toimintaan aktivoitumisesta. [Information behaviour of older adults. Qualitative study on information practices and enactment in everyday life]. Oulu: Oulu University Press. Available at: http://jultika.oulu.fi/files/isbn9514282906.pdf

Niemelä, R.; Ek, S.; Eriksson-Backa, K. \& Huotari, M.-L. (2012). A Screening Tool for Assessing Everyday Health Information Literacy. Libri, 62, 125-134.

Nikou, S. (2015). Mobile technology and forgotten consumers: the young-elderly International Journal of Consumer Studies, 39(4), 294-304.

Noblin, A.M. (2010) Intention to use a personal health record (PHR): A cross sectional view of the characteristics and opinions of patients of one internal medicine practice. $\mathrm{PhD}$ Thesis, College of Health and Public Affairs at the University of Central Florida Orlando, Florida. Available at: http://etd.fcla.edu/CF/CFE0003046/Noblin_Alice_M_201005_PhD.pdf

Pálsdóttir, Á. (2008). Information behaviour, health self-efficacy beliefs and health behaviour in Icelanders'everyday life. Information Research 13(1), paper 334. Available at: http://informationr.net/ir/13-1/paper334.html

Pew Research Center (2013). Health Online 2013. Available at: http://www.pewinternet.org/files/old-media//Files/Reports/PIP_HealthOnline.pdf 
Pratt, W., Unruh, K., Civan, A. \& Skeels, M. (2006). Personal health information management. Communications of the ACM, 49(1), 51-55.

http://faculty.washington.edu/wpratt/Publications/CACMp51-pratt.pdf

Regeringen (2016). Vision e-hälsa 2025 - gemensamma utgångspunkter för digitalisering $i$ socialtjänst och hälso- och sjukvård [Vision eHealth 2025 - common premises for digitalisation of social services and healthcare]. Stockholm: Regeringskansliet.

Renahy, E., Parizot, I. \& Chauvin, P. (2008). Health information seeking on the internet: a double divide? Results from a representative survey in the Paris metropolitan area, France, 2005-2006. BMC Public Health 8(69).

Rexhepi, H.; Åhlfeldt, R.-M.; Cajander, Å. \& Huvila, I. (2016). Cancer patients' attitudes and experiences of online access to their electronic medical records: A qualitative study. In print in Health Informatics Journal.

Romero, F. P.; Caballero, I.; Serrano-Guerrero, J. \& Olivas, J. A. (2012). An approach to webbased Personal Health Records filtering using fuzzy prototypes and data quality criteria. Information Processing \& Management, 2012, 48(3), 451-466.

Sanchiz, M.; Chin, J.; Chevalier, A.; Fu, W. T.; Amadieu, F. \& He, J. (2017). Searching for information on the web: Impact of cognitive aging, prior domain knowledge and complexity of the search problems. Information Processing \& Management, 53(1), 281-294.

Scandurra, I.; Jansson, A.; Forsberg-Fransson, M.-L. \& Ålander, T. (2017). Patient Accessible EHR is Controversial: Lack of Knowledge and Diverse Perceptions Among Professions. International Journal of Reliable and Quality E-Healthcare (IJRQEH), 6(1), 29-45.

Shaw, N. (2013). Content validation for level of use of feature rich systems: a Delphi study of electronic medical records systems. Information Research, 18(1).

Sparks, L. \& Nussbaum, J.F. (2008). Health literacy and cancer communication with older adults. Patient Education and Counseling 71(3), 345-350.

Sørensen, K., Van den Brouvke, S., Fullam, J., Doyle, G., Pelikan, J., Slonska, Z., Brand, H. and (HLS-EU) Consortium Health Literacy Project European (2012). Health literacy and public health: A systematic review and integration of definitions and models. BMC Public Health http://bmcpublichealth.biomedcentral.com/articles/10.1186/1471-2458-12-80

Stanberry, K. (2011). US and global efforts to expand the use of electronic health records. Records Management Journal, 21(3), 214-224.

Statistics Sweden (2012). Yearbook of Educational Statistics 2013. Örebro.

Suri, V. R.; Chang, Y.-K.; Majid, S. \& Foo, S. (2014). Health Information Literacy of Senior Citizens - A Review. Kurbanoğlu, S.; Špiranec, S.; Grassian, E.; Mizrachi, D. \& Catts, R. (Eds.) Proceedings of the ECIL 2014, Springer, 128-137. 
Taha, J., Sharit, J. \& Czaja, S. (2009). Use for and satisfaction with sources of health information among older Internet users and nonusers. The Gerontologist 49(5), 663-673.

Vance, B., Tomblin, B., Studeny, J., \& Coustasse A. (2015). Benefits and barriers for adoption of personal health records. Paper presented at the 2015 Business and Health Administration Association Annual Conference, at the 51st Annual Midwest Business Administration Association International Conference, Chicago, IL.

http://mds.marshall.edu/cgi/viewcontent.cgi?article=1135\&context=mgmt_faculty

Walker, D. M.; Johnson, T.; Ford, E. W. \& Huerta, T. R. (2017). Trust me, I'm a doctor: examining changes in how privacy concerns affect patient withholding behavior. Journal of Medical Internet Research 19, e2.

Weibull, L.; Oscarsson, H. \& Bergström, A. (eds.) (2011). Svenska trender 1986-2011 [Swedish trends 1986-2011]. Göteborg: SOM-institutet.

WHO (2015). World report on ageing and health. Geneva: World Health Organization.

Woods, S. S.; Schwartz, E.; Tuepker, A.; Press, N. A.; Nazi, K. M.; Turvey, C. L. \& Nichol, W. P. (2013). Patient Experiences With Full Electronic Access to Health Records and Clinical Notes Through the My HealtheVet Personal Health Record Pilot: Qualitative Study. J Med Internet Res, $15(3), \mathrm{e} 65$.

Wrzus, C., Hänel, M., Wagner, J. \& Neyer, F.J. (2013). Social network changes and life events across the life span: a meta-analysis. Psychological Bulletin 139(1), 53-80.

Wu, J.-R., Moser, D.K., DeWalt, D.A., Rayens, M.K., Dracup, K. (2016). Health Literacy Mediates the Relationship Between Age and Health Outcomes in Patients With Heart Failure. $J$ Circulation: Heart Failure. 9 (1):e002250

https://doi.org/10.1161/CIRCHEARTFAILURE.115.002250

Yan, Y. Y. (2010). Online health information seeking behavior in Hong Kong: an exploratory study. Journal of Medical Systems 34(2), 147-153.

Yates, C.; Stoodley, I.; Partridge, H.; Bruce, C.; Cooper, H.; Day, G. \& Edwards, S. L. (2012). Exploring Health Information Use by Older Australians within Everyday Life. Library Trends, 2012, 60(3), 460-478.

Young, R., Willis, E., Cameron, G., \& Geana, M. (2014). "Willing but unwilling”: attitudinal barriers to adoption of home-based health information technology among older adults. Health Informatics Journal 20(2), 127-135.

Zarcadoolas, C., Vaughon, W. L., Czaja, S. J., Levy, J., \& Rockoff, M. L. (2013) Consumers' perceptions of patient-accessible electronic medical records. J Med Internet Res 15(8), e168.

Zhang, Y. (2014). Beyond quality and accessibility: Source selection in consumer health information searching. JASIST, 2014, 65(5), 911-927. 
Zickuhr, K. \& Madden, M. (2012). Older Adults and internet use: for the first time, half of adults age 65 and older are online, Pew Research Center, Washington, DC [online]

http://www.pewinternet.org/2012/06/06/older-adults-and-internet-use/ 